Tropical Journal of Pharmaceutical Research September 2020; 19 (9): 1933-1939

ISSN: $1596-5996$ (print); 1596-9827 (electronic)

(C) Pharmacotherapy Group, Faculty of Pharmacy, University of Benin, Benin City, 300001 Nigeria.

Original Research Article

http://dx.doi.org/10.4314/tjpr.v19i9.19

\title{
Ameliorative and anti-arthritic potential of arjunolic acid against complete Freund's adjuvant-induced arthritis in rats
}

\author{
Yi Fan, Cheng Zhang, Guotao Zheng, Shuai Wu, Yujie Wang, Jinsong Bian* \\ Department of Orthopedics, Cangzhou People's Hospital, Cangzhou, Hebei 061000, China
}

*For correspondence: Email: czbjs2018@sina.com; Tel: +86-3173521078

Sent for review: 21 April 2020

Revised accepted: 25 August 2020

\begin{abstract}
Purpose: To determine the anti-arthritic effect of arjunolic acid against complete Freund's adjuvant (CFA)-induced arthritis in rats.

Methods: Arthritis was induced in male Sprague Dawley rats by intradermal injection of $0.1 \mathrm{~mL}$ of CFA at the right footpad. Upon induction of osteoarthritis, arjunolic acid was administered via oral gavage at doses of 40 and $80 \mathrm{mg} / \mathrm{kg}$ once daily for 25 successive days. Indomethacin was used as reference drug at a dose of $3 \mathrm{mg} / \mathrm{kg}$ via gavage twice weekly for 25 days. Changes in paw swelling, serum hematology, antioxidant enzymes, serum inflammatory mediators, and histopathology were determined using standard procedures.

Results: Paw swelling and weight loss in CFA-induced arthritic rats were significantly reversed ( $p<$ $0.01)$ by arjunolic acid. Malondialdehyde (MDA) levels, spleen index and thymus index were significantly reduced in CFA-induced arthritic rats $(p<0.01)$. Moreover, arjunolic significantly increased superoxide dismutase (SOD), catalase (CAT), and glutathione peroxidase (GPx) activities, while downregulating the expressions of TNF- $\alpha, I L-1 \beta$ and IL-6 in serum $(p<0.01)$. The hematological and histopathological changes due to CFA-induced arthritis were ameliorated by arjunolic acid.

Conclusion: The results obtained in this study indicate that arjunolic acid may possess therapeutic potentials for the management of arthritis.
\end{abstract}

Keywords: Arjunolic acid, Triterpenoid; Oxidative stress, osteoarthritis, Inflammation

\begin{abstract}
This is an Open Access article that uses a fund-ing model which does not charge readers or their institutions for access and distributed under the terms of the Creative Commons Attribution License (http://creativecommons.org/licenses/by/4.0) and the Budapest Open Access Initiative (http://www.budapestopenaccessinitiative.org/read), which permit unrestricted use, distribution, and reproduction in any medium, provided the original work is properly credited.

Tropical Journal of Pharmaceutical Research is indexed by Science Citation Index (SciSearch), Scopus, International Pharmaceutical Abstract, Chemical Abstracts, Embase, Index Copernicus, EBSCO, African Index Medicus, JournalSeek, Journal Citation Reports/Science Edition, Directory of Open Access Journals (DOAJ), African Journal Online, Bioline International, Open-J-Gate and Pharmacy Abstracts
\end{abstract}

\section{INTRODUCTION}

The bioactive constituents of medicinal plants are regarded as promising candidates for pharmaceutical research. The demand for drugs derived from natural products has increased over the years [1]. Complementary and alternative medicines from plants are gaining interest among researchers due to their effectiveness and non- toxic nature. Bioactive compounds from plants are diverse in nature and function, especially with regard to pharmaceutical occupancy [2]. The basis of bioactivity of a phytochemical compound is its antioxidant effect, a parameter which determines its medicinal value. Polyphenols, flavonoids, and terpenoids are among the common phytochemical compounds that have 
been studied for their pharmacological properties $[3,4]$.

Arjunolic acid is a chiral triterpenoid compound found in Terminalia arjuna Roxb. tree, a popular medicinal plant in the field of Ayurvedic and other traditional practices. Arjunolic acid has been shown to exert multiple therapeutic effects such as anti-diabetic, hepatoprotective, nephroprotective, cardioprotective, anti-microbial, anti-cholinesterase, wound-healing, anti-tumor, and anti-asthmatic properties [5-7]. These therapeutic effects have been shown to occur through modulation of signaling pathways involved in oxidative stress and inflammation, including MAPKs, Bcl-2/Bax, NF-k $\beta$ and PARP $[6,7]$.

Osteoarthritis is a degenerative joint disorder characterized by derangement of articular cartilage, inflammation of synovial membrane, and degeneration of subchondral bone [8]. People affected by osteoarthritis experience problems of disability, morbidity, and limitations in movements due to severe pain. Inflammatory responses triggered by pro-inflammatory cytokines are reported to play a part in the pathogenesis of osteoarthritis [9]. Inflammation damages the neighboring cells surrounding the articular cartilage, thereby spreading the disease to the surrounding tissues. Inflammation is associated with oxidative stress. Indeed, it has been reported that osteoarthritic animal models manifested oxidative stress conditions [10]. The present study was aimed at evaluating the antiarthritic and ameliorative effects of arjunolic acid on complete Freund's adjuvant (CFA)-induced arthritis in rats.

\section{EXPERIMENTAL}

\section{Chemicals}

Arjunolic acid, Complete Freud's Adjuvant (CFA), and analytical reagents and chemicals were obtained from Sigma Aldrich, US, while ELISA commercial assay kits, reagents, and commercial kits for enzymatic and protein studies were obtained from R\&D Systems, Minneapolis, US. All reagents used were pure analytical grade.

\section{Experimental animals}

Sprague-Dawley rats weighing 150-180 g and aged 6-8 weeks, were acclimatized at room temperature $\left(25 \pm 2^{\circ} \mathrm{C}\right)$ under continuous light/dark cycle in a well-ventilated environment. The rats were permitted ad libitum access to drinking water and standard diet. The animal experimental procedures were performed according to the guidelines and approval provided by animal ethical committee of Cangzhou People's Hospital (approval no. IECAF20190501) in line with the requirements of the Principles of Laboratory Animal Care $(\mathrm{NIH}$ publication no. 85-23, revised 1985) [11].

\section{Experimental procedure}

Five groups of rats were used (6 rats per group): control rats (group 1), CFA-induced arthritic model rats (group II), model rats treated with arjunolic acid at doses of 40 and $80 \mathrm{mg} / \mathrm{kg}$ body weight (bwt; groups III and IV, respectively), and positive control group given reference drug indomethacin at a dose of $3 \mathrm{mg} / \mathrm{kg}$ bwt (group V). On the first day, arthritis was induced in every group (except control group) via intradermal injection of CFA $(0.1 \mathrm{ml})$ at the right hind footpad. Rats in groups III and IV were orally administered arjunolic acid through intragastric gavage at doses of 40 and $80 \mathrm{mg} / \mathrm{kg}$ bwt, respectively, for 25 successive days following induction of arthritis. Rats in the positive control group (group $\mathrm{V})$ received indomethacin via oral gavage twice in a week for 25 days.

Paw swelling and arthritis index were calculated at 5-day intervals for 25 days, using a plethysmometer (UGO Basile 37140, Italy). Arthritis scoring was done by a blinded observer who was naïve to the experimental groups and treatments. The arthritic score ranged from 0 (no swelling) to 4 (severe swelling), for all four paws, up to a maximum score of 16 for each rat. On completion of the experiment, the rats were sedated with isoflurane and euthanized using cervical dislocation. Blood and ankle joint samples were obtained for biochemical and histopathological studies. Spleen index and thymus index of the rats were estimated as ratios of wet organ weights to final body weights. Hematological profiles of blood samples were determined using laboratory automated analyzer (Sysmex XP-300, Germany) in line with the manufacturer's guide and standard protocols [12].

\section{Serum and tissue biochemical analyses}

Samples of blood withdrawn from the femoral artery were placed at room temperature to coagulate, and then centrifuged for 15 minutes at $3000 \mathrm{rpm}$. The serum samples obtained were subjected assay of levels of pro-inflammatory cytokines i.e. TNF- $\alpha, \mathrm{IL}-1 \beta$ and IL-6 using commercial ELISA assay kits in line with the manufacturer's guidelines [13]. Tissues from excised ankle joints were homogenized in icecold $10 \%$ phosphate buffer, $\mathrm{pH} 7.4$, and 
centrifuged at $4{ }^{\circ} \mathrm{C}$ for 30 minutes at $10000 \mathrm{rpm}$. The supernatants were used for assay of the antioxidant enzymes GPx, SOD and CAT, as well as levels of MDA using standard assay kits (Sigma Aldrich, US), according to the kit instructions [14]. Protein levels in tissue extracts were determined with Bradford assay, with bovine serum albumin as standard.

\section{Histopathological studies}

Ankle joint tissues were fixed in $10 \%$ neutral buffered formalin, $\mathrm{pH}$ 7.2, trimmed and decalcified in $10 \%$ EDTA for 30 days at $4{ }^{\circ} \mathrm{C}$. Thereafter, the tissues were embedded in paraffin and sliced into 4- $\mu \mathrm{m}$ sections which were stained with hematoxylin and eosin (H\&E). The stained sections were visualized under a light microscope and photomicrographs of relevant features were obtained.

\section{Statistical analysis}

The data are expressed as mean \pm standard error of mean (SEM, $n=6$ ). Statistical analysis was carried out using one-way analysis of variance (ANOVA) together with Dunnett's multiple comparison analysis. All statistical analyses were done using SPSS version 22.0. Significance of differences were assumed at $p<$ 0.05 .

\section{RESULTS}

\section{Effect of arjunolic acid on some parameters of CFA-induced arthritis in rats}

Intradermal injection of CFA into right footpad of rats caused severe paw swelling and increases in paw volume (Figure 1). Paw swelling in model group (group II) continued to increase over the period of 25 days $(p<0.05)$. However, arjunolic acid administration resulted in significant reductions in paw swelling in group III and IV arthritic rats after two weeks $(p<0.01)$. Similarly, there was decreased paw volume in rats treated with indomethacin (positive control group) after two weeks $(p<0.01)$. The arthritic score for rats in the model group was significantly higher than that of rats in control group, due to evident swelling, inflammation, and paw deformation (Figure 2). Arthritic scores were clearly decreased in arjunolic acid-treated rats in groups III and IV as from day 14, when compared to rats in the model group. The arthritic scores of rats in the positive control group were significantly lower as from day 14 than the corresponding scores of rats in the model group.

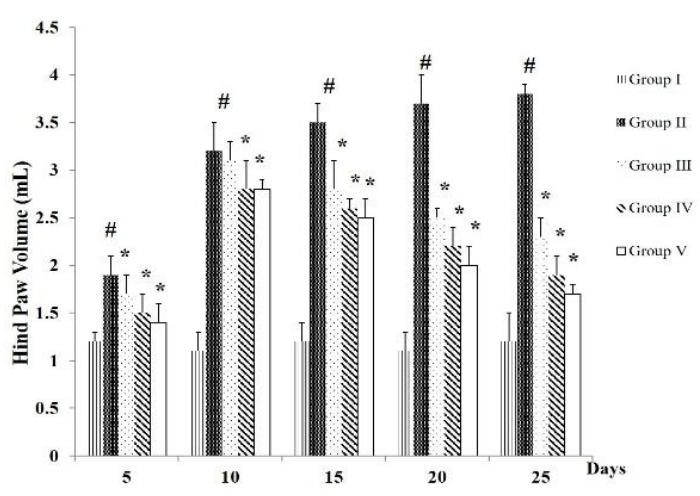

Figure 1: Effect of arjunolic acid on paw volume of CFA-induced arthritic rats. Results are presented as mean \pm SEM $(n=6)$; $\# p<0.05$, compared to normal group; ${ }^{*} p<0.01$, compared to arthritic model group

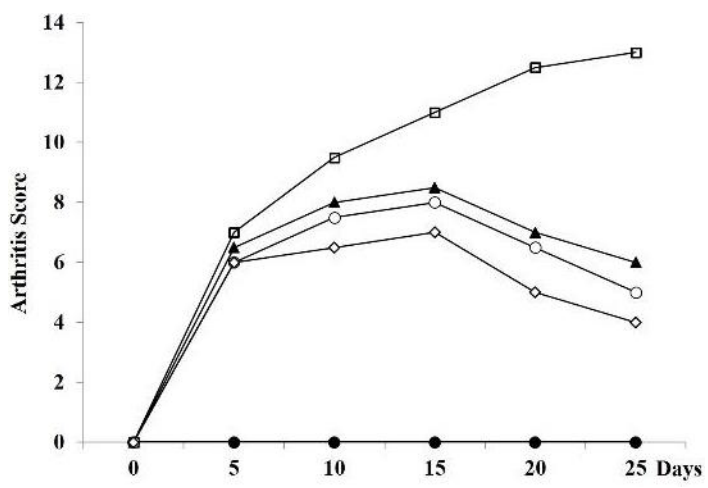

Figure 2: Effect of arjunolic acid on arthritis score of CFA-induced arthritic rats. Results are expressed as mean $\pm \operatorname{SEM}(n=6)$. The arthritic score ranged from 0 (no swelling) to 4 (severe swelling) in all four paws of each rat, with a maximum score of 16 for each rat.

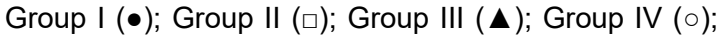
Group V $(\diamond)$

\section{Effect of arjunolic acid on body weight, spleen index and thymus index}

The mean body weight of rats in the model group (group II) was markedly reduced, when compared to the body weight of rats in the control group I $(p<0.05)$. However, arjunolic acid treatment resulted in increases in the body weights of rats in groups III and IV, relative to rats in group II $(p<0.01)$. Spleen index and thymus index were markedly increased in the CFA-induced arthritic rats (group II), when compared to rats in normal control group I $(p<$ $0.05)$. However, arjunolic acid reduced the organ index values in rats of group III and IV, when compared with rats in group II $(p<0.01)$. Rats in the positive control group (indomethacin-treated rats) had higher body weights and lower organ index values than those in model group $(p<$ $0.01)$. These results are presented in Table 1. 
Table 1: Effect of arjunolic acid on body weight, spleen index and thymus index of CFA-induced arthritic rats

\begin{tabular}{|c|c|c|c|}
\hline Group & $\begin{array}{l}\text { Final } \\
\text { body } \\
\text { weight } \\
\text { (g) }\end{array}$ & $\begin{array}{c}\text { Spleen } \\
\text { index } \\
(\mathrm{mg} / \mathrm{g})\end{array}$ & $\begin{array}{c}\text { Thymus } \\
\text { index } \\
\text { (mg/g) }\end{array}$ \\
\hline Normal control & $\begin{array}{c}208.31 \pm \\
4.16\end{array}$ & $\begin{array}{c}2.73 \pm \\
0.15\end{array}$ & $\begin{array}{c}1.36 \pm \\
0.12\end{array}$ \\
\hline $\begin{array}{l}\text { CFA-induced } \\
\text { model group }\end{array}$ & $\begin{array}{c}153.24 \pm \\
11.54^{\#}\end{array}$ & $\begin{array}{c}3.96 \pm \\
0.11^{\#}\end{array}$ & $\begin{array}{l}1.97 \pm \\
0.14^{\#}\end{array}$ \\
\hline $\begin{array}{l}\text { Arjunolic acid } \\
40 \mathrm{mg} / \mathrm{kg}+ \\
\text { CFA }\end{array}$ & $\begin{array}{c}181.82 \pm \\
6.28^{*}\end{array}$ & $\begin{array}{c}3.17 \pm \\
0.12^{*}\end{array}$ & $\begin{array}{l}1.72 \pm \\
0.11^{*}\end{array}$ \\
\hline $\begin{array}{l}\text { Arjunolic acid } \\
80 \mathrm{mg} / \mathrm{kg}+ \\
\text { CFA }\end{array}$ & $\begin{array}{c}193.85 \pm \\
5.72^{*}\end{array}$ & $\begin{array}{c}2.85 \pm \\
0.14^{*}\end{array}$ & $\begin{array}{l}1.53 \pm \\
0.10^{*}\end{array}$ \\
\hline $\begin{array}{l}\text { Indomethacin } 3 \\
\mathrm{mg} / \mathrm{kg}+\mathrm{CFA}\end{array}$ & $\begin{array}{c}201.68 \pm \\
8.32^{*}\end{array}$ & $\begin{array}{c}2.78 \pm \\
0.12^{*}\end{array}$ & $\begin{array}{l}1.41 \pm \\
0.08^{*}\end{array}$ \\
\hline
\end{tabular}

\section{Effect of arjunolic acid on hematological} parameters in CFA-induced arthritic rats

As shown in Table 2, there were significant changes in WBC counts and erythrocyte sedimentation rate, and marked decreases in hemoglobin and RBC counts in the CFA-induced arthritic rats, with significant increases in WBC counts, relative to rats in the normal group $(p<$ 0.05). However, arjunolic acid reduced the WBC counts and erythrocyte sedimentation rate, and increased the RBC and hemoglobin counts of rats in groups III and IV, when compared to rats in model group $(p<0.01)$. Moreover, the hematological changes caused by CFA were significantly reversed by indomethacin treatment (positive control rats), relative to model group ( $p$ $<0.01$ ).

\section{Effect of arjunolic acid on oxidative stress markers in CFA-induced arthritic rats}

There were significant decreases in activities of the antioxidant enzymes GPx, SOD, and CAT in the CFA-induced arthritic rats, while MDA level was significantly increased, when compared to normal control rats $(p<0.05)$. However, the effects of CFA on oxidative stress markers were reversed by arjunolic acid in groups III and IV, resulting in restoration of the activities of the antioxidant enzymes, and reduction in MDA level, when compared to rats in the model group $(p<0.01)$. The levels of oxidative stress markers were also restored in the positive control group treated with indomethacin, when compared to model group $(p<0.01)$. These results are shown in Table 3.

Table 2: Effect of arjunolic acid on hematological changes in CFA-induced arthritic rats

\begin{tabular}{lcccc}
\hline Group & Hb $(\mathbf{m g ~ \% )}$ & WBC $\left(\times 10^{3} / \mathbf{m m}^{3}\right)$ & RBC $\left(\times 10^{6} / \mathbf{m m}^{3}\right)$ & ESR $(\mathbf{m m} / \mathbf{h})$ \\
\hline Normal control & $16.2 \pm 0.51$ & $5.6 \pm 0.33$ & $9.8 \pm 0.28$ & $10.2 \pm 0.38$ \\
CFA-induced model group & $11.7 \pm 0.53^{\#}$ & $11.3 \pm 0.42^{\#}$ & $6.1 \pm 0.53^{\#}$ & $15.1 \pm 0.52^{\#}$ \\
Arjunolic acid 40 mg/kg + & $13.5 \pm 0.62^{*}$ & $8.8 \pm 0.47^{*}$ & $7.7 \pm 0.31^{*}$ & $13.5 \pm 0.41^{*}$ \\
CFA & & & & \\
Arjunolic acid 80 mg/kg + & $15.1 \pm 0.84^{*}$ & $7.5 \pm 0.50^{*}$ & $8.6 \pm 0.27^{*}$ & $12.1 \pm 0.54^{*}$ \\
CFA & $15.8 \pm 0.44^{*}$ & $6.2 \pm 0.36^{*}$ & $9.2 \pm 0.45^{*}$ & $11.4 \pm 0.30^{*}$ \\
Indomethacin 3 mg/kg + & & & & \\
CFA & & & & \\
\hline
\end{tabular}

Results are presented as mean \pm SEM of rats $(n=6)$. $\# p<0.05$, compared to normal control group; ${ }^{*} p<0.01$, compared to model group II. ESR = erythrocyte sedimentation rate; $\mathrm{RBC}=$ red blood cells; $\mathrm{Hb}=$ hemoglobin; WBC $=$ white blood cells

Table 3: Effect of arjunolic acid on oxidative stress in CFA-induced arthritic rats

\begin{tabular}{|c|c|c|c|c|}
\hline Group & $\begin{array}{l}\text { MDA (nmol/mg } \\
\text { protein }\end{array}$ & $\begin{array}{l}\text { GPx (U/mg } \\
\text { protein) }\end{array}$ & $\begin{array}{l}\text { SOD }(U / m g \\
\text { protein) }\end{array}$ & $\begin{array}{l}\text { CAT (U/mg } \\
\text { protein) }\end{array}$ \\
\hline Normal control & $4.31 \pm 0.31$ & $32.58 \pm 1.42$ & $45.57 \pm 1.91$ & $20.19 \pm 1.71$ \\
\hline $\begin{array}{l}\text { CFA-induced model } \\
\text { group }\end{array}$ & $9.88 \pm 0.38^{\#}$ & $17.32 \pm 1.57^{\#}$ & $32.62 \pm 3.72^{\#}$ & $11.32 \pm 1.90^{\#}$ \\
\hline $\begin{array}{l}\text { Arjunolic acid } 40 \text { mg/kg + } \\
\text { CFA }\end{array}$ & $6.94 \pm 0.22^{*}$ & $24.88 \pm 1.94^{*}$ & $37.70 \pm 2.32^{*}$ & $15.25 \pm 1.22^{*}$ \\
\hline $\begin{array}{l}\text { Arjunolic acid } 80 \mathrm{mg} / \mathrm{kg}+ \\
\text { CFA }\end{array}$ & $5.65 \pm 0.36^{*}$ & $27.45 \pm 1.76^{*}$ & $39.86 \pm 2.28^{*}$ & $17.14 \pm 1.58^{*}$ \\
\hline $\begin{array}{l}\text { Indomethacin } 3 \mathrm{mg} / \mathrm{kg}+ \\
\text { CFA }\end{array}$ & $5.17 \pm 0.24^{*}$ & $29.16 \pm 1.58^{*}$ & $42.22 \pm 2.51^{*}$ & $18.84 \pm 1.40^{*}$ \\
\hline
\end{tabular}

Results are presented as mean \pm SEM $(n=6)$. \#p < 0.05, compared to normal control group; ${ }^{*} p<0.01$, compared to model group II. MDA = malondialdehyde; GPx = glutathione peroxidase; SOD = superoxide dismutase; CAT = catalase 
Table 4: Effect of arjunolic acid on serum levels of pro-inflammatory cytokines

\begin{tabular}{lccc}
\hline Group & TNF- $\alpha(\mathbf{p g} / \mathbf{m L})$ & IL-1 $\beta(\mathbf{p g} / \mathbf{m L})$ & IL-6 $(\mathbf{p g} / \mathbf{m L})$ \\
\hline Normal control & $64.24 \pm 8.86$ & $141.38 \pm 12.56$ & $128.14 \pm 13.62$ \\
CFA-induced model group & $145.26 \pm 13.80^{\#}$ & $188.17 \pm 12.80^{\#}$ & $244.22 \pm 12.78^{\#}$ \\
Arjunolic acid 40 mg/kg + CFA & $113.56 \pm 12.51^{*}$ & $169.36 \pm 13.54^{*}$ & $187.41 \pm 12.96^{*}$ \\
Arjunolic acid 80 mg/kg + CFA & $96.28 \pm 9.32^{*}$ & $157.37 \pm 12.68^{*}$ & $162.45 \pm 13.68^{*}$ \\
Indomethacin 3 mg/kg + CFA & $75.42 \pm 8.64^{*}$ & $149.72 \pm 13.18^{*}$ & $148.44 \pm 12.72^{*}$ \\
\hline \multicolumn{2}{l}{ Results are presented as mean \pm SEM $(\mathrm{n}=6) . \# p<0.05$, compared to normal control group; ${ }^{*} p<0.01$, } \\
\multicolumn{2}{l}{ compared to model group }
\end{tabular}

\section{Effect of arjunolic acid on serum levels of pro-inflammatory cytokines}

Table 4 shows that serum levels of proinflammatory cytokines IL-1 $\beta$, TNF- $\alpha$ and IL-6 were significantly elevated in CFA-induced arthritic model rats, when compared to normal control rats $(p<0.05)$. However, arjunolic acid treatment resulted in reduced levels of these proinflammatory cytokines in rats in groups III and IV, when compared to rats in model group $(p<$ 0.01). Similarly, indomethacin treatment significantly decreased the serum levels of the pro-inflammatory cytokines, relative to the untreated against model rats $(p<0.01)$.

\section{Effect of arjunolic acid on histopathological changes in arthritic rats}

The histopathology of ankle joints of normal control group rats showed normal articular surface and healthy joint space and synovial tissues. In contrast, CFA-induced model group rats showed evidence of osteoarthritis and inflammation, with infiltration of inflammatory cells at the joints, synovial lining hyperplasia, articular cartilage damage, and abnormal bone degeneration (Figure 3).
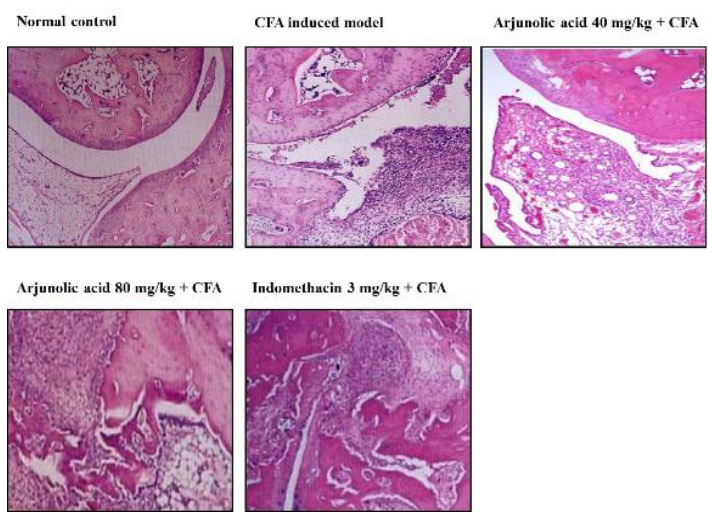

Figure 3: Effect of arjunolic acid on ankle joint histopathology of CFA-induced arthritic rats. Ankle joint section of CFA-induced arthritic model showing severe signs of abnormal bone cartilage degeneration, synovial hyperplasia and massive infiltration of inflammatory cells. Administration of arjunolic acid and indomethacin ameliorated the CFA-induced arthritic conditions (H\&E staining, $\times 100)$
However, arjunolic acid administration to rats in groups III and IV resulted in marked reduction in hyperplasia of synovial lining, decreased infiltration of inflammatory cells, and preservation of bone and cartilage structures at the joints. Indomethacin administration also exhibited protective effects against CFA-induced arthritic and inflammatory conditions.

\section{DISCUSSION}

Therapeutic approaches for osteoarthritic conditions are turning towards natural productderived drugs. Animal model studies on evaluation of the potential of new antiosteoarthritis drugs usually use CFA for induction of arthritis [15]. This has provided evidence for the therapeutic potential of arjunolic acid in a CFA-induced arthritic rat model. Arjunolic acid has been well-established as an antioxidant and anti-inflammatory agent in various studies involving pathological conditions. Osteoarthritis is associated with inflammatory reactions and oxidative stress. Thus, based on its antioxidant and anti-inflammatory properties, arjunolic acid has therapeutic significance for osteoarthritis. It was noteworthy that arjunolic acid at high dose (80 $\mathrm{mg} / \mathrm{kg}$ ) was able to reduce CFA-induced increase in paw volume to a level comparable to the effect produced by the positive control drug indomethacin.

Moreover, arjunolic acid reduced organ index values and increased the body weight of CFAinduced arthritic rats in a dose-dependent manner. The CFA-induced arthritis in rats is due to an immune-mediated inflammatory reaction in the form of cell-mediated immunity [16]. The secondary lesion and paw swelling due to CFAinduced arthritis caused were significantly reduced by arjunolic acid, as shown in the arthritis scores. The reductions in thymus index and spleen index also showed that the immune reaction triggered by CFA was suppressed by arjunolic acid. This is consistent with the reduction in paw swelling and arthritic scores.

Significant increases in the levels of WBC are usually seen in arthritic conditions due to 
stimulatory effects arising from increased IL-1 $\beta$ levels [12]. A similar result was seen in CFAinduced arthritic rats in which WBC counts were reduced by administration of arjunolic acid and indomethacin. The CFA-induced hematological alterations such as increased erythrocyte sedimentation rate and decreased RBC and hemoglobin counts, were reversed to normal by arjunolic acid in a manner comparable to that of indomethacin.

Decreased hemoglobin levels in arthritic conditions are due to reduced erythropoietin concentration, diminished activity of bone marrow erythropoietin, and pre-mature lysis of $\mathrm{RBC}$. An increase in erythrocyte sedimentation rate indicates a doubtful disease process characterized by accelerated formation of endogenous proteins [15]. The hematological changes that occur during arthritis are due to increases in spleen index and thymus index. The ameliorative effect of arjunolic acid on the hematological changes and organ index values point to its immunosuppressive and anti-arthritic effects against adjuvant-induced arthritis.

Oxidative stress in arthritic conditions is demonstrated through reduced activities of antioxidant enzymes and elevated levels of lipid peroxidation in the tissues [17]. The activities of GPx, SOD, and CAT were reduced, whereas MDA level was elevated in the CFA-induced arthritic rats, indicating that the rats were subjected to oxidative stress. Oxidative stress due to inadequate antioxidant supply creates cellular disruptions which lead to pathological changes seen in osteoarthritis $[10,18]$. Inflammatory responses are triggered by oxidative stress through activation of NF-k $\beta$ and MAPK pathways [19]. The activation of these pathways enhances the secretion of large amounts of pro-inflammatory cytokines by inflammatory cells.

The pro-inflammatory cytokines TNF- $\alpha$, IL- $1 \beta$, and IL-6 are important progenitors in the pathogenesis of arthritis [20]. They contribute to the inflammation at ankle and knee joints in osteoarthritic conditions, and they tend to damage the articular cartilages and bone, causing synovial tissue inflammation and other pathological changes [21]. These changes are triggered in a cascade of events initiated by oxidative stress and hematological changes due to arthritis [22]. Pathological features of osteoarthritis and increased levels of proinflammatory cytokines were observed in the results of histology and ELISA assay in CFAinduced arthritic rats. These changes were significantly reversed by arjunolic acid in a dosedependent manner.

Arjunolic acid, an antioxidant triterpenoid compound, was able to prevent oxidative stress through inhibition of lipid peroxidation and maintenance of the activities of antioxidant enzymes. The anti-inflammatory potential of arjunolic acid was revealed through suppression of pro-inflammatory cytokines. The anti-arthritic effects of arjunolic acid was evident in the reversal of the CFA-induced pathological changes in rat ankle joints, in a manner similar to that of the reference drug indomethacin.

\section{CONCLUSION}

Arjunolic acid exhibits anti-arthritic potential against CFA-induced arthritis in rats via its ameliorative effects on hematological changes, oxidative stress, inflammation, and pathological lesions. The anti-arthritic effects of arjunolic acid are due to its antioxidant and anti-inflammatory properties. Therefore, arjunolic acid has potentials for use as a novel therapeutic agent for osteoarthritis.

\section{DECLARATIONS}

\section{Conflict of interest}

No conflict of interest is associated with this work.

\section{Contribution of authors}

We declare that this work was done by the authors named in this manuscript and all liabilities pertaining to claims relating to the content of this article will be borne by the authors. Manuscript writing and editing by $Y F$, $\mathrm{CZ}, \mathrm{GZ}, \mathrm{JB}$; data collection and analysis by $\mathrm{YF}$, CZ, GZ, SW, YW; experimental design and methods were provided by JB.

\section{Open Access}

This is an Open Access article that uses a funding model which does not charge readers or their institutions for access and distributed under the terms of the Creative Commons Attribution License (http://creativecommons.org/licenses/by/ 4.0) and the Budapest Open Access Initiative (http://www.budapestopenaccessinitiative.org/rea d), which permit unrestricted use, distribution, and reproduction in any medium, provided the original work is properly credited. 


\section{REFERENCES}

1. Wang SX, Abramson SB, Attur M, Karsdal MA, Preston RA, Lozada CJ, Kosloski MP, Hong F, Jiang P, Saltarelli MJ, Hendrickson BA, Medema JK. Safety, tolerability, and pharmacodynamics of an anti-interleukin-1 $\alpha / \beta$ dual variable domain immunoglobulin in patients with osteoarthritis of the knee: A randomized phase 1 study. Osteoarthr Cartil 2017; 25(12): 1952-1961.

2. Costa R, Ragusa S, Russo M, Certo G, Franchina FA, Zanotto A, Grasso E, Mondello L, Germano MP. Phytochemical screening of Artemisia arborescens L. by means of advanced chromatographic techniques for identification of health-promoting compounds. J Pharm Biomed Anal 2016; 117: 499-509.

3. Lin B, Zhao $Y$, Han P, Yue W, Ma XQ, Rahman K, Zheng CJ, Qin LP, Han T. Anti-arthritic activity of Xanthium strumarium L. extract on complete Freund's adjuvant induced arthritis in rats. J Ethnopharmacol 2014; 155(1): 248-255.

4. Wu Y, Goh EL, Wang D, Ma S. Novel treatments for osteoarthritis: A recent update. Open Access Rheumatol 2018; 10: 135-140.

5. Ghosh J, Sil PC. Arjunolic acid: A new multifunctional therapeutic promise of alternative medicine. Biochimie 2013; 95: 1098-1109.

6. Manna P, Sil PC. Arjunolic acid: Beneficial role in type 1 diabetes and its associated organ pathophysiology. Free Radic Res 2012; 46: 815-830.

7. Miriyala S, Chandra M, Maxey B, Day A, Clair DKS, Panchatcharam M. Arjunolic acid ameliorates reactive oxygen species via inhibition of $p 47$ phox-serine phosphorylation and mitochondrial dysfunction. Int $J$ Biochem Cell Biol 2015; 68: 70-77.

8. Poulet $B$, Staines KA. New developments in osteoarthritis and cartilage biology. Curr Opin Pharmacol 2016; 28: 813.

9. Wojdasiewicz P, Poniatowski LA, Szukiewicz D. The role of inflammatory and anti-inflammatory cytokines in the pathogenesis of osteoarthritis. Mediators Inflamm 2014; 2014: 561459.

10. Chang X, He H, Zhu L, Gao J, Wei T, Ma Z, Yan T. Protective effect of apigenin on Freund's complete adjuvant-induced arthritis in rats via inhibiting P2X7/NFKB pathway. Chem Biol Interact 2015; 236: 41-46.

11. National Research Council (US) Committee for the Update of the Guide for the Care and Use of Laboratory Animals. Guide for the Care and Use of Laboratory Animals. 8th edition, Washington (DC): National
Academies Press (US); 2011. Key Concepts. Available from: https://www.ncbi.nlm.nih.gov/books/NBK54054/

12. Patil KR, Patil CR, Jadhav RB, Mahajan VK, Patil PR, Gaikwad PS. Anti-arthritic activity of bartogenic acid isolated from fruits of Barringtonia racemosa Roxb. (Lecythidaceae). Evid-Based Compl Alt Med 2011; 2011: 1-7.

13. Wang S, Wang Y, Liu X, Guan L, Yu L, Zhang X. Antiinflammatory and anti-arthritic effects of taraxasterol on adjuvant-induced arthritis in rats. I Ethnopharmacol 2016; 187: 42-48.

14. Jeong JH, Moon SJ, Jhun JY, Yang EJ, Cho ML, Min JK. Eupatilin exerts antinociceptive and chondroprotective properties in a rat model of osteoarthritis by downregulating oxidative damage and catabolic activity in chondrocytes. PLoS One 2015; 10: e0130882.

15. Zheng CJ, Zhao XX, Ai HW, Lin B, Han T, Jiang YP, Xing $X$, Qin LP. Therapeutic effects of standardized Vitex negundo seeds extract on complete Freunds adjuvant induced arthritis in rats. Phytomed 2014; 21(6): 838-846.

16. Lima-Garcia JF, Dutra RC, da Silva K, Motta EM, Campos MM, Calixto JB. The precursor of resolvin $D$ series and aspirin-triggered resolvin D1 display antihyperalgesic properties in adjuvant-induced arthritis in rats. Brit J Pharmacol 2011; 164(2): 278-293.

17. Zhang L, Zhu M, Li M, Du Y, Duan S, Huang Y, Lu Y, Zhang J, Wang T, Fu F. Ginsenoside Rg1 attenuates adjuvant-induced arthritis in rats via modulation of PPAR-y/NF-KB signal pathway. Oncotarget 2017; 8(33): 55384-55393.

18. Qiao YQ, Jiang PF, Gao YZ. Lutein prevents osteoarthritis through Nrf2 activation and downregulation of inflammation. Arch Med Sci 2018; 14 : 617-624.

19. Hou SM, Hou CH, Liu JF. CX3CL1 promotes MMP-3 production via the CX3CR1, c-Raf, MEK, ERK, and NF$K B$ signaling pathway in osteoarthritis synovial fibroblasts. Arthritis Res Ther 2017; 19(1): 282.

20. Rahmati M, Mobasheri A, Mozafari M. Inflammatory mediators in osteoarthritis: A critical review of the stateof-the-art, current prospects, and future challenges. Bone 2016; 85: 81-90.

21. Wang CC, Guo L, Tian FD, An N, Luo L, Hao RH, Wang $B$, Zhou ZH. Naringenin regulates production of matrix metalloproteinases in the knee-joint and primary cultured articular chondrocytes and alleviates pain in rat osteoarthritis model. Braz J Med Biol Res 2017; 50: e5714. 